\title{
Piston kinematics of a combustion engine with unconventional crank mechanism
}

\author{
Pavol Kukuča ${ }^{1}$, Dalibor Barta ${ }^{1,1,}$ Ján Dižo ${ }^{1}$, Jacek Caban ${ }^{2}$ \\ ${ }^{1}$ University of Žilina, Department of Transport and Handling Machines, Faculty of Mechanical \\ Engineering, Univerzitná 1, 01026 Žilina, Slovakia \\ ${ }^{2}$ University of Life Science in Lublin, Faculty of Production Engineering, 28 Głęboka Street 20-612 \\ Lublin, Poland
}

\begin{abstract}
The article deals with a theoretical solution of kinematic variables describing the movement of a combustion engine piston with unconventional mechanism FIK protected by patents No. 283742 and No. 283743 [1]. The course of the path, the velocity, and the acceleration were calculated to assess the dynamic properties of the unconventional mechanism, which transform the piston linear movement to rotational movement by using a swinging board, a baseboard and a crankshaft.
\end{abstract}

Keywords: Combustion engine, unconventional crank mechanism, piston, kinematics, swinging board

\section{Introduction}

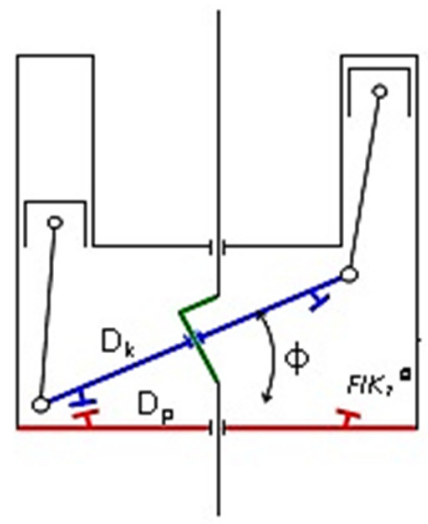

Fig. 1. Scheme of the unconventional engine mechanism

\footnotetext{
${ }^{1}$ Corresponding author: dalibor.barta@fstroj.uniza.sk

Reviewers: Pawel Drozdziel, Plamen Punov
} 
Current trends lead to the use of various innovative technologies in vehicle drives. They aim to reduce the weight and dimensions of engines, as well as their vibration and noise.

In combination with the development and improvement of material and fuel technologies, new and uncommon solutions find application [2-4]. The applications of unconventional solutions are often utilized in stationary machines like generators, cogeneration units etc. before being implemented in automobiles, where the requirements for reliability and comfort is much higher. Stirling engine [5, 6], cycloidal internal combustion engine mechanism of Shih [7], which have a low frontal area, very good balance and great compactness [8-10] are examples of using of unconventional mechanisms. Kinematic parameters of unconventional mechanism FIK, also applicable in such engines, are described in this paper.

\section{Kinematics of the piston movement}

Piston path is mostly specified by the path of the observed point on the swinging board, where the articulated connecting rod is mounted. Its size, similar to the classical crank mechanism, is affected by the connecting rod length and position of the cylinder axis in relation to the crankshaft axis. For the next considerations the cylinder axis is situated parallel to the axis of the crank shaft and simultaneously in the plane of the crank (see Fig. 1). The cylinder axis intersects the plane $\mathbf{X Y}$ approximately in the center of the observed point trajectory in the same plane. In such a position $(\alpha=0)$ the piston is in the bottom dead centre. The cylinder axis can practically be situated in a random position and it may not be parallel to the axis of the crankshaft.

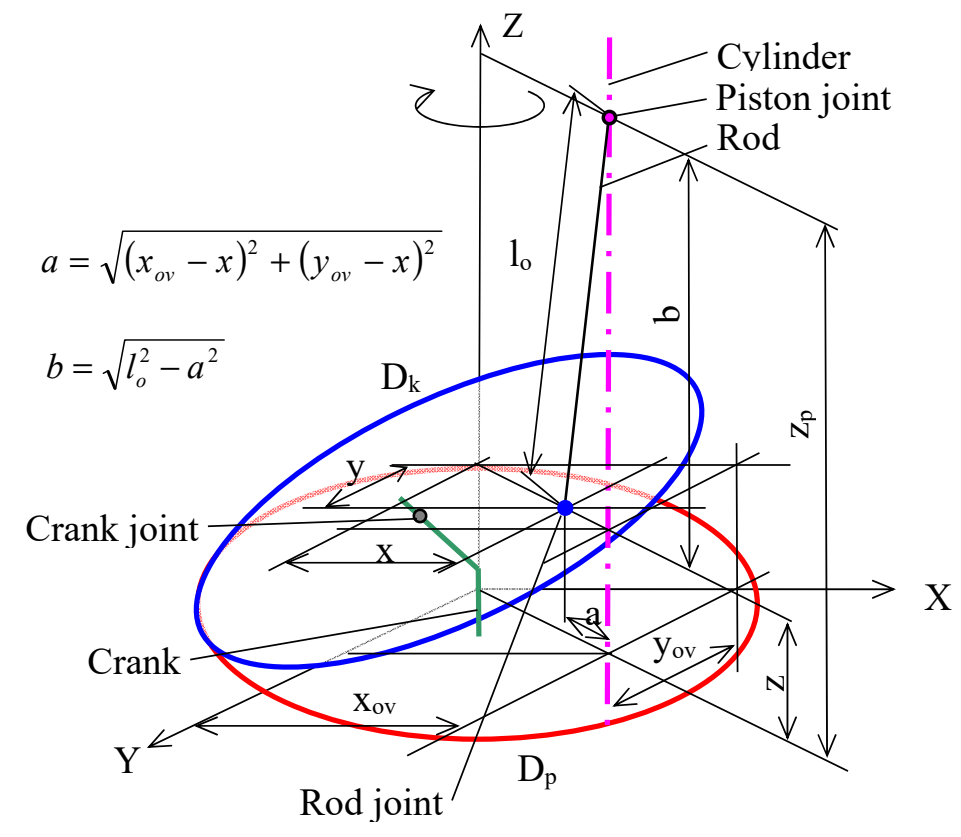

Fig. 2. Scheme of the unconventional engine mechanism FIK $_{1}$

The graphical scheme of the unconventional mechanism on Fig. 2 is the basis for the following deduction of the piston path expression. 
The scheme on the Fig. 2 shows, that the piston position (path of the piston joint) in the $\mathbf{Z}$ axis direction is given by the sum of the rod joint position $z$ and the distance $b$ according to the equation:

$$
z_{p}=z+b=z+\sqrt{l_{o}^{2}-\left(x_{o v}-x\right)^{2}-\left(y_{o v}-y\right)^{2}},
$$

where

$x_{o v}$ - position of the cylinder axis in the $\mathrm{X}$ direction,

$y_{o v}$ - position of the cylinder axis in the $\mathrm{Y}$ direction,

$l_{o}$ - rod length.

After derivation with respect to time of expression and appropriate modification, the velocity of the piston joint is

$$
c_{p}=\frac{d z_{p}}{d t}=c_{z}+\frac{c_{x} \cdot\left(x_{o v}-x\right)+c_{y} \cdot\left(y_{o v}-y\right)}{\sqrt{l_{o}^{2}-\left(x_{o v}-x\right)^{2}-\left(y_{o v}-y\right)^{2}}},
$$

where

$\mathrm{c}_{\mathrm{x}}, \mathrm{c}_{\mathrm{y}}, \mathrm{c}_{\mathrm{z}}$ - the velocities of observed point in axes $\mathrm{X}, \mathrm{Y}$, and $\mathrm{Z}$ defined as:

$$
\begin{gathered}
c_{x}=\frac{d x}{d t}=\frac{d x}{d \alpha} \cdot \frac{d \alpha}{d t}=\omega \cdot(1-\cos \phi) \cdot\left[R_{k o} \cdot\left(1-2 \cdot \sin ^{2} \alpha\right)-R \cdot \cos \phi\right] \\
c_{y}=\frac{d y}{d t}=\frac{d y}{d \alpha} \cdot \frac{d \alpha}{d t}=\omega \cdot(1-\cos \phi) \cdot\left(2 \cdot R_{k o} \cdot \sin \alpha \cdot \cos \alpha-R \cdot \sin \alpha\right) \\
c_{z}=\frac{d z}{d t}=\frac{d z}{d \alpha} \cdot \frac{d \alpha}{d t}=\omega \cdot R_{k o} \cdot \sin \alpha \cdot \sin \phi
\end{gathered}
$$

The piston joint acceleration is obtained as a time derivative of the velocity. After appropriate modification the relation is:

$$
\begin{aligned}
a_{p}=\frac{d c_{p}}{d t} & =a_{z}+\frac{\left(x_{o v}-x\right) \cdot a_{x}+\left(y_{o v}-y\right) \cdot a_{y}-\left(c_{x}^{2}+c_{y}^{2}\right)}{\sqrt{l_{o}^{2}-\left(x_{o v}-x\right)^{2}-\left(y_{o v}-y\right)^{2}}}- \\
& -\frac{\left[\left(x_{o v}-x\right) \cdot c_{x}+\left(y_{o v}-y\right) \cdot c_{y}\right]^{2}}{\left[\sqrt{l_{o}^{2}-\left(x_{o v}-x\right)^{2}-\left(y_{o v}-v\right)^{2}}\right]^{3}}
\end{aligned}
$$

where

$a_{x}, a_{y}, a_{z}$ - the accelerations of observed point in axes $\mathrm{X}, \mathrm{Y}$, and $\mathrm{Z}$ defined as:

$$
\begin{gathered}
a_{x}=\frac{d^{2} x}{d t^{2}}=\frac{d^{2} x}{d \alpha^{2}} \cdot\left(\frac{d \alpha}{d t}\right)^{2}=\omega^{2} \cdot(1-\cos \phi) \cdot\left(R \cdot \sin \alpha-4 \cdot R_{k o} \cdot \sin \alpha \cdot \cos \alpha\right) \\
a_{y}=\frac{d^{2} y}{d t^{2}}=\frac{d^{2} y}{d \alpha^{2}} \cdot\left(\frac{d \alpha}{d t}\right)^{2}=\omega^{2} \cdot(1-\cos \phi) \cdot\left[2 \cdot R_{k o} \cdot\left(1-2 \cdot \sin ^{2} \alpha\right)-R \cdot \cos \alpha\right]
\end{gathered}
$$




$$
a_{z}=\frac{d^{2} z}{d t^{2}}=\frac{d^{2} z}{d \alpha^{2}} \cdot\left(\frac{d \alpha}{d t}\right)^{2}=\omega^{2} \cdot R_{k o} \cdot \cos \alpha \cdot \sin \phi
$$

The results of calculations for the same basic parameters as previously stated are on the following pictures. Fig. 3 shows the course of the piston joint path $z_{p}$ in relation to the angle of the crank rotation $\alpha$ and also in comparison with the connecting rod joint path $z$ (observed point on the swinging board). By comparing both curves it is clear, that the swinging movement of the connecting rod causes small change in the course of the piston stroke in comparison to the stroke of the connecting rod joint. The velocity of the piston joint $c_{p}$ together with the velocity of the connecting rod joint $c_{z}$ is shown in Fig. 4, in order to review the influence of the swinging movement of the connecting rod and cylinder axis position on the piston velocity. Comparing the velocities, it is possible to see, that the design parameters influence also in this case the piston joint velocity to slightly higher values. It is possible to partially eliminate this influence by the appropriate rod length selection, appropriate cylinder axis location, as well as correct rod joint position on the swinging board.

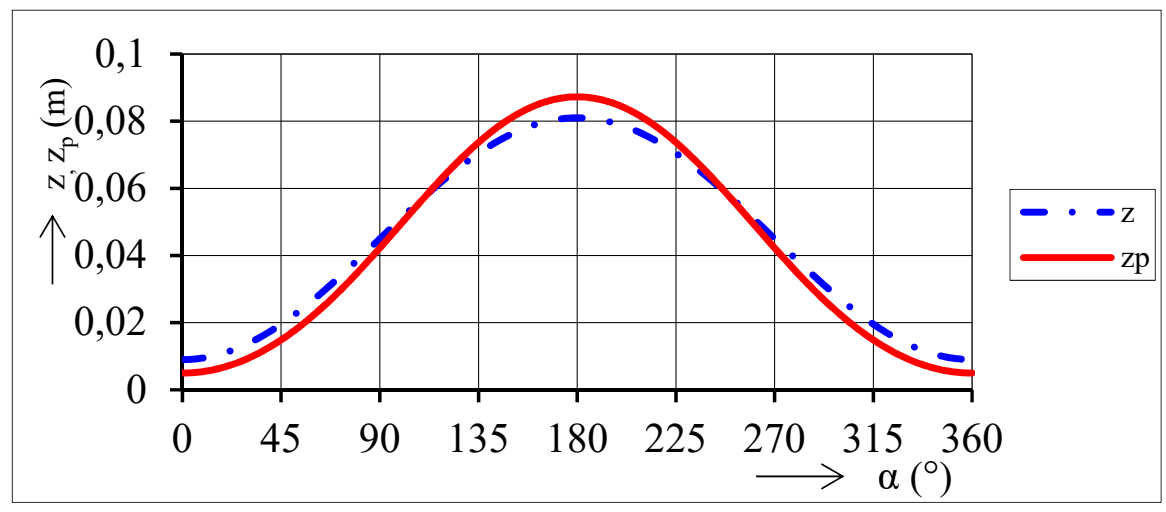

Fig. 3. Path of the piston joint $z_{p}$ point in relation to the angle of the crank rotation $\alpha$

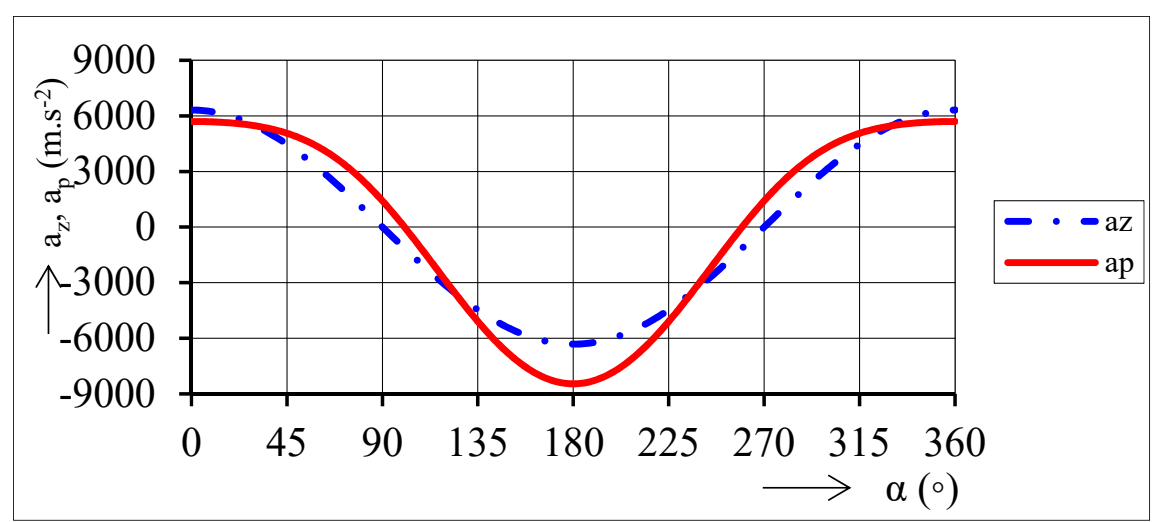

Fig. 4. Velocity of the piston joint $c_{p}$ in relation to the angle of the crank rotation $\alpha$ 


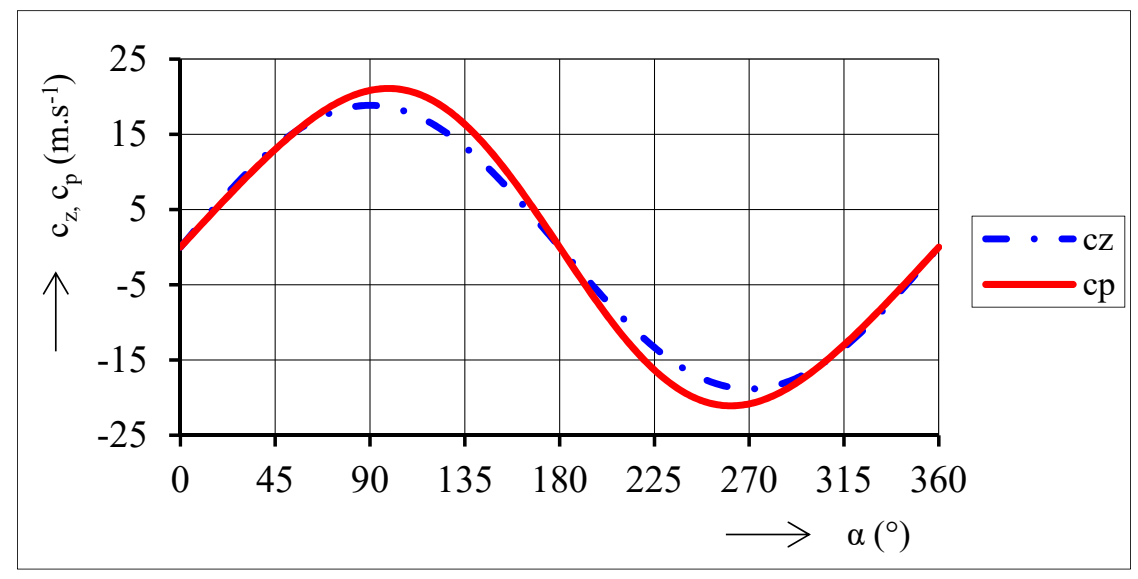

Fig. 5. Acceleration of the piston joint $a_{p}$ in relation to the angle of the crank rotation $\alpha$

Fig. 5 shows acceleration $a_{p}$ of the piston joint in dependence on the angle of the crank shaft rotation. Simultaneously, for better presentation, the acceleration $a_{z}$ of the connecting rod joint on the swinging board is shown in the diagram. By comparing both accelerations it can be concluded that, in this case the design parameters also have some influence on the piston joint acceleration, which has a slight value increase in comparison to rod joint acceleration. Similar to the velocity case, it is possible to partially eliminate this influence by adopting appropriate mechanism design.

Particular examples of the visual solution of such an engine are shown in Fig. 6, Fig. 7 and Fig. 8.

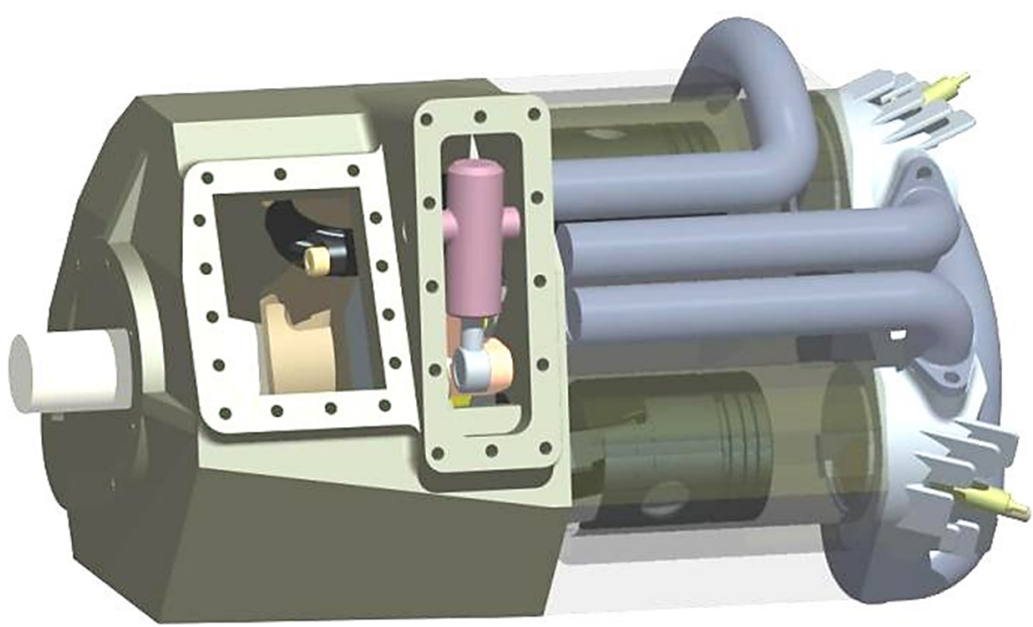

Fig. 6. Virtual model of the engine with unconventional mechanism FIK 


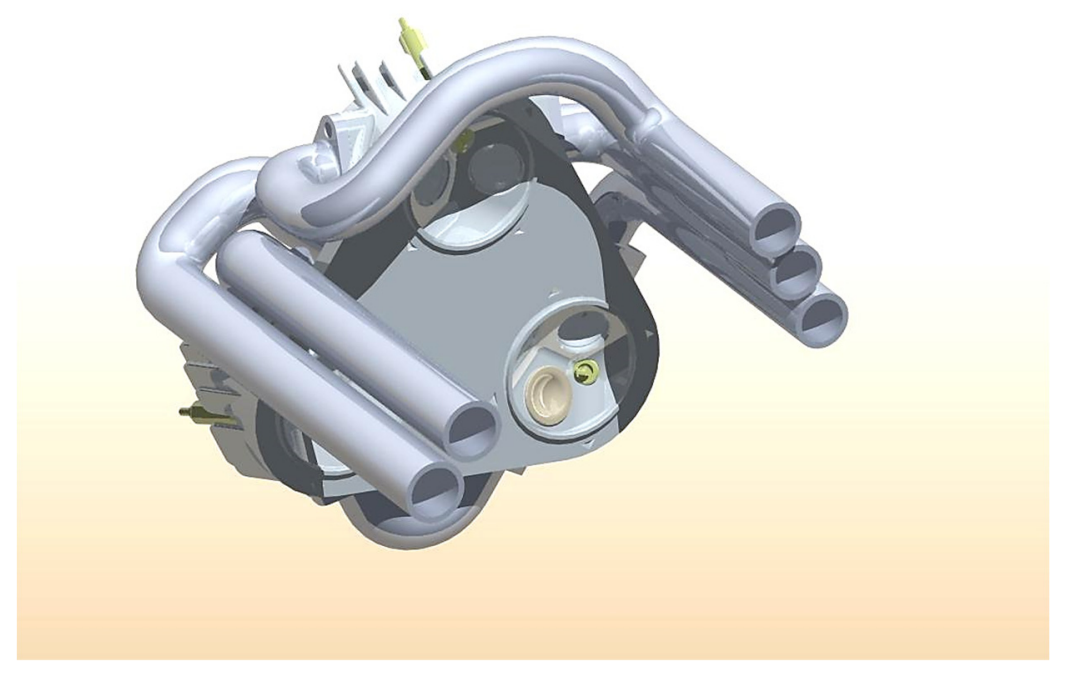

Fig. 7. Internal arrangement of the engine with FIK mechanism

The view on the internal arrangement of the FIK mechanism, where the swinging plate is replaced by a special swinging plate with three arms for the movable attachment of connecting rods, is shown in Fig. 7.

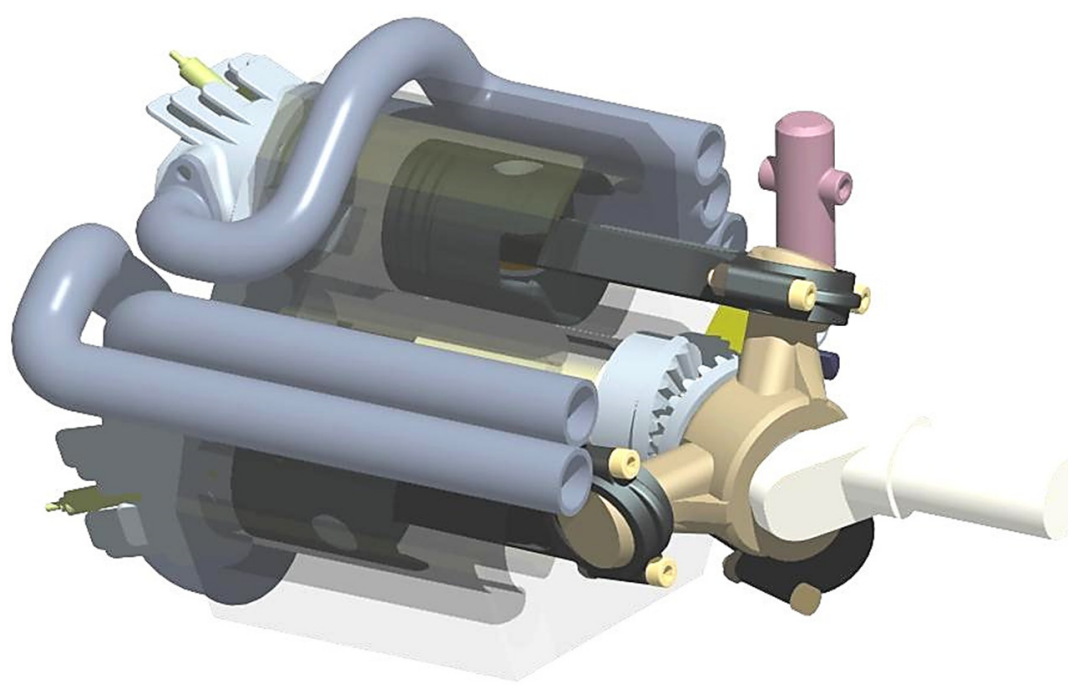

Fig. 8. The cylinder head with intake and exhaust pipes of the engine with FIK mechanism 


\section{Conclusion}

As shown the calculations, the kinematic properties of the engine with FIK unconventional crank mechanism are comparable to the kinematic properties of the classical piston combustion engine with the same value of the piston stroke. This solution has the potential to reduce the wear of the cylinder and the noise caused by the tilting of the piston due to the small deflection of the connecting rod from the vertical axis of the piston. The piston kinematics parameters can be influenced by adjusting the distance of the between the crankshaft axis and the axis of the cylinder. When comparing the kinematic values of a classical engine and a FIK engine with the same stroke and at the same revolutions, the values for the FIK engine are about $10 \%$ higher.

This paper was realized as a part of the project KEGA 022ŽU-4/2017 - Implementation of on-line education in the area of precise technologies with an impact on educational process to increase skills and flexibility of students of engineering fields of study and as a result of the project implementation: "Modern methods of teaching of control and diagnostic systems of engine vehicles", ITMS code 26110230107, supported by the Operational Programme Education.

\section{References}

1. P. Fitz, R. Istenik, P. Kukuca, Mechanizmus piestového stroja, Vestník ÚPV SR, patent č. 283742, (12/2003)

2. S. Erkaya, İ. Uzmay, Experimental investigation of joint clearance effects on the dynamics of a slider-crank mechanism, Multibody System Dynamics, vol. 24, Issue 1, p. 81-102, (2010)

3. Z. Bo, S. Fei, A numerical coupling model for a multibody system with multiple lubricated clearance joints, MATEC Web of Conferences 108, 15006, (2017)

4. M. A.A.Fenelon, T. Furukawa, Design of an active flapping wing mechanism and a micro aerial vehicle using a rotary actuator, Mechanism and Machine Theory, vol. 45, p. 137146, (2010)

5. P. Baran, P. Stastniak, M. Brezani, Dynamic analysis and comparison of balancing systems of nonconventional piston machine FIK. Proceeding of conference: Dynamics of rigid and deformable bodies 2016. Usti nad Labem, p. 9-15, (2016)

6. D. Barta, J. Saniga, M. Mruzek, M. Kendra, Design of selected parts of non-conventional Stirling engine with FIK mechanism, TOJSAT, 3, Issue 2, (2013)

7. J. Shih, Kinematics of the Cycloidal Internal Combustion Engine Mechanism, Journal of mechanical design, vol. 115 (4), p. 953-959, (2008)

8. Axial Internal-Combustion Engines, http://www.douglas-self.com/MUSEUM/POWER /unusualICeng/axial-ICeng/axial-IC.htm, (2008)

9. R. Isteník, Simulácia mechanických a termomechanických procesov v spal'ovacích motoroch a vozidlách, Habilitation thesis, KKVMZ SjF Žilinská univerzita, (2002)

10. P. Punov, T. Evtimov, Research influence of various geometrical parameters on the gasoline engine performance, Proceedings of 15th International conference of Quality and reliability on technical systems, Nitra, Slovakia, p. 42-51, (2010). 